http://dx.doi.org/10.18593/ejjl.v18i1.8610

\title{
APORIAS DA FUNDAMENTAÇÃO CONVENCIONAL DOS DIREITOS HUMANOS E OS CAMINHOS DA INTERCULTURALIDADE
}

\author{
DIFFICULTIES OF CONVENTIONAL JUSTIFICATION OF HUMAN RIGHTS AND THE PATHWAYS OF \\ INTERCULTURALITY
}

Vicente de Paulo Barretto 1

Fernanda Frizzo Bragato ${ }^{2}$

\begin{abstract}
Resumo: A fundamentação dos direitos humanos é uma tarefa própria do campo de investigação filosófica que pretende, de um lado, refletir sobre a razão da existência desses direitos e, de outro, estabelecer os argumentos que the conferem validade e legitimidade. Neste trabalho não se pretende responder diretamente às questões de existência e legitimidade dos direitos humanos. Os objetivos são, de um lado, demonstrar que a fundamentação é condição para a efetividade dos direitos humanos e, de outro, que existe um discurso convencional de fundamentação, filiado a pressupostos teóricos de matriz racional-individualista, que é, ao mesmo tempo, dominante e incongruente porque restringe as possibilidades de proteção universal desses direitos. Dominante porque a ele se filia grande parte dos jusfilósofos do Ocidente, entre eles o próprio Norberto Bobbio, os quais produzem a mais vasta e influente literatura sobre o tema. Incongruente porque o conceito de humanidade proposto pelo marco racional-individualista falha ao justificar a pretensa universalidade dos direitos humanos. A apropriação da noção de interculturalidade, por outro lado, pode constituir o ponto de partida para a construção de discursos de fundamentação que estejam atentos a realidades culturalmente plurais. $O$ presente artigo é resultado parcial das investigações do Projeto de Pesquisa CNPq-Universal n. 476114/2013-6 Os Direitos Humanos no contexto Latino-americano: do caráter universal à interculturalidade integrado pelos autores.
\end{abstract}

Palavras-chave: Fundamentação. Direitos humanos. Racionalidade. Individualismo. Interculturalidade.
Abstract: The justification of human rights is a characteristically philosophical-oriented task that aims, on one hand, to reflect on the reason for the existence of these rights and, on the other hand, to establish the arguments that grant it validity and legitimacy. Rather than answering those questions directly, this work intends to demonstrate that the justification is a condition for the effectiveness of human rights and that there is a conventional discourse of justification linked to rational-individualist theoretical framework, which is, at the same time, dominant and incongruous. Dominant because it is replicated by most of the Western jusphilosophers, including Norberto Bobbio, who produce the broadest and most influential literature on the subject. Incongruous because the concept of humanity proposed by the rational-individualist framework fails in justifying the alleged universality of human rights. The appropriation of the notion of interculturality, however, can be the starting point for the formulation of discourses of justification that are committed to culturally plural realities and vulnerable people demands. This article is a partial outcome of the investigations that have been carried out by the authors in the Research Project CNPq-Universal n. 476114/20136 , titled Human rights in the Latin American context: from universality to interculturality.

Keywords: Justification. Human rights. Rationality. Individualism. Interculturality.

\footnotetext{
1 Pós-doutor pela Maison des Sciences de L’Homme, Paris; Doutor em Direito pela Pontifícia Universidade Católica do Rio de Janeiro; Livre-docente em Filosofia pela Pontifícia Universidade Católica do Rio de Janeiro; Professor do Programa de Pós-graduação em Direito na Universidade Estácio de Sá; Professor do Programa de Pós-graduação em Direito na Universidade do Vale do Rio dos Sinos; Rua São José, 35, 15ª andar, Centro, 20010-020, Rio de Janeiro, Brasil; vpbarreto@terra.com.br

2 Pós-doutora pelo Birkbeck College na Universidade de Londres; Doutora em Direito pela Universidade do Vale dos Sinos; Professora do Programa de Pós-graduação em Direito na Universidade do Vale do Rio dos Sinos; Av. Unisinos, 950, Cristo Rei, 93022-000, São Leopoldo, Rio Grande do Sul, Brasil; fernanda_bragato@hotmail.com
} 


\section{Introdução}

Neste artigo discutimos o problema da necessidade de fundamentação dos direitos humanos diante da relação existente entre efetividade e discursos de legitimação, de um lado, e da predominância de um discurso dominante, de outro, propondo, ao final, a introdução da noção de interculturalidade como caminho para a propositura de novas discussões sobre o tema.

Consideramos que a tese de Norberto Bobbio sobre a inutilidade de fundamentar os direitos humanos é extremamente influente em nosso País e vem contribuindo para que muitos estudiosos deixem a tarefa de lado ou, como o próprio autor da tese, reputem-na um problema já resolvido. Pretendemos demonstrar que a fundamentação não apenas é um campo em disputa, como é também condição necessária para a efetividade dos direitos humanos. Em nossa pesquisa, procuramos demonstrar que a tese de Bobbio está ancorada na suposta indiscutibilidade da fundamentação jusracionalista dos direitos humanos que é, de fato, a mais influente, mas profundamente problemática. Além de delinear os principais contornos dessa fundamentação, pretendemos apontar suas falhas ligadas à construção da figura do humano que dá suporte à definição do sujeito de direitos da modernidade.

A noção de interculturalidade é introduzida, ao final, como proposta teórica para reconfigurar discursos de fundamentação dos direitos humanos. De um lado, a noção de interculturalidade relativiza a importância ou a centralidade do legado europeu-moderno para a definição de padrões éticos e epistemológicos e, portanto, para a construção política e filosófica dos direitos humanos. De outro, é uma ideia aberta à perspectiva de indivíduos e grupos vulnerabilizados e estigmatizados em sociedades desiguais e plurais, como é o caso da América Latina. Este artigo é resultado parcial das pesquisas realizadas pelos autores no âmbito do Projeto de Pesquisa financiado pelo Edital CNPq-Universal sob o n. 476114/2013-6 e intitulado Os Direitos Humanos no contexto Latino-americano: do caráter universal à interculturalidade.

\section{Da necessidade de justificação dos direitos humanos}

É amplamente conhecida e influente entre os estudiosos brasileiros a posição de Norberto Bobbio de que os direitos humanos prescindem de fundamentação, pois o seu problema reside na inefetividade: "o problema fundamental em relação aos direitos do homem, hoje, não é tanto o de justificá-los, mas o de protegê-los. Trata-se de um problema não filosófico, mas político." (BOBBIO, 2004, p. 24). Nas palavras do autor a fundamentação é considerada um problema já resolvido desde a proclamação, em 1948, da Declaração Universal dos Direitos Humanos:

quando digo que o problema mais urgente que temos que enfrentar não é problema da fundamentação, mas o das garantias, quero dizer que consideramos o problema da fundamentação não como inexistente, mas como - em certo sentido - resolvido, ou seja, como um problema cuja solução já não devemos mais nos preocupar. Com efeito, pode-se dizer que o problema da fundamentação dos direitos 
humanos teve sua solução atual na Declaração Universal dos Direitos Humanos, aprovada pela Assembléia Geral da ONU, em 10 de dezembro de 1948. (BOBBIO, 2004, p. 26).

Para Bobbio, duas são as razões para que se deixe de lado a investigação sobre a justificação de direitos que pretendem se credenciar não apenas como critérios de validade de ordens jurídicas justas, mas como repositório do ideal de vida digna de toda a humanidade. A primeira delas é o fato de que tais direitos carecem de efetividade; consequentemente, deve-se concentrar esforços para resolver um problema de ordem política e não filosófica. A segunda é que o problema filosófico já está resolvido por meio da proclamação de um documento aprovado por um órgão político de cunho internacional (ONU) que obteve um consenso em torno de algumas normas destinadas a proteger os seres humanos. Ou seja, não é necessário discutir a sua indiscutível validade enquanto o seu problema é de eficácia.

Partilhamos com Rosillo Martínez (2013) o entendimento de que, ao sugerir que o problema em relação aos direitos humanos não é de fundamentação, mas de busca de meios de garantia, Bobbio comete vários equívocos.

Em relação ao problema da falta de efetividade, não se pode negar que Bobbio tenha razão. Os direitos humanos são amplamente desrespeitados em qualquer lugar (Ocidente, Oriente, Norte, Sul, interior de qualquer Estado, esfera pública ou privada, etc.), variando as modalidades de violação e os sujeitos afetados. No entanto, a inefetividade nem sempre está ligada a questões de ordem executiva que emperram a sua implementação, como ausência de leis, regulamentos, pessoal de apoio, órgãos de governo ou qualquer outro fator técnico. E nesse ponto reside seu primeiro equívoco.

A inefetividade pode estar ligada a um problema que antecede a práxis: a falta de razões convincentes que legitimem e incentivem a observância dos direitos humanos, o que se constrói discursivamente no nível da fundamentação. Mesmo que filiado à mesma concepção convencional dos direitos humanos, Pérez Luño (1995) diz que embora o problema prioritário em relação aos direitos humanos seja não tanto a sua justificação, mas as condições de sua proteção, esse é um problema que desemboca no da fundamentação. Segundo o autor, o argumento que reputa desnecessário um discurso de fundamentação ignora o fato de que a constante violação atual dos direitos humanos mostra a precariedade dessas pretendidas "convicções geralmente compartilhadas", de que fala Bobbio, e que, portanto, há a necessidade de seguir argumentando em seu favor (PÉREZ LUÑO, 1995, p. 133).

A Declaração Universal dos Direitos Humanos assume diversas premissas necessárias à aceitação geral das normas que institui e que, de fato, devem sustentar o seu dever de obediência. Porém, não é possível dizer que elas estejam claramente fundamentadas ou fora de disputa. Em seus artigos primeiro e segundo, o documento estabelece suas principais premissas: todos são igualmente dignos, têm os mesmos direitos e, portanto, suas inúmeras distinções não impedem a capacidade de gozar os direitos e as liberdades previstos no documento. Sabemos que a dignidade inerente a todos os seres humanos é uma premissa moral, mas não um fato natural. Disso decorre a necessidade de saber por 
que todos os seres humanos são igualmente dignos, como se construiu historicamente essa ideia, que contexto permitiu a sua afirmação. Ou seja, não há consenso sobre questões morais que fornecem as razões de justificação dos direitos humanos, como é o caso da dignidade humana. Além de haver diferentes conceitualizações em torno dessa ideia - umas mais influentes que outras -, há também inúmeras teorias que se contrapõem a ela e, portanto, não apenas inexiste consenso, como há resistência e razões para que os direitos humanos sejam propositalmente inobservados e desprotegidos.

De modo que em relação à suposta indiscutibilidade da fundamentação dos direitos humanos assentada no consenso obtido no documento de 1948, Bobbio parece ter ignorado que quando este foi elaborado não houve o mesmo consenso no que se refere às razões que justificavam o seu conjunto de normas. A Declaração Universal dos Direitos Humanos foi aprovada por unanimidade, porém os países comunistas (União Soviética, Ucrânia e Rússia Branca, Tchecoslováquia, Polônia e Iugoslávia), a Arábia Saudita e a África da Sul abstiveram-se de votar (COMPARATO, 2003, p. 223). Não obstante as abstenções, ela representou apenas um denominador comum entre as diversas concepções em torno dos problemas teóricos que suscitava. Esse acordo ocorreu na forma da aceitação de um conjunto de direitos mínimos e, principalmente, de mecanismos de controle, garantidores dos direitos, consagrados pelos Estados signatários da Declaração (BARRETTO, 2004, p. 281). Além disso, mesmo que um texto normativo tenha sido elaborado, seus vários sentidos continuam em construção, tanto que desde a Declaração houve um processo de paulatina expansão de direitos humanos que já não traduzem o mesmo conjunto de normas a que se chegou em 1948. A Declaração, portanto, não resolveu o problema da fundamentação dos direitos humanos. ${ }^{3}$

A questão em torno da necessidade de fundamentação permanece. Problemas de efetividade têm relação direta com dúvidas sobre "para quem", "para quê", "por quê" e "de onde vem" os direitos humanos. Essas não são questões resolvidas, como supunha Bobbio, e tampouco irrelevantes para a construção da teoria dos direitos humanos. Fundamentar e proteger são tarefas interdependentes.

Fundamenta-se para proteger e só fundamentando se pode ter uma ideia clara do que se quer proteger ou daquilo pelo qual se quer lutar. Não fundamentar tem um efeito semelhante às fundamentações dogmáticas que é o de hipostasiar os direitos humanos já reconhecidos, desvinculando-os da práxis humana e situando-os em um âmbito a-histórico. Com isso, seus conteúdos normativos e critérios de legitimidade política se tornam alheios aos processos históricos de cada povo e os direitos humanos se transformam facilmente em instrumentos de dominação e opressão. (ROSILLO MARTÍNEZ, 2013, p. 30).

\footnotetext{
3 A elaboração da Declaração Universal dos Direitos Humanos de 1948 foi precedida pela organização de consultas, encomendadas pela Comissão de Direitos do Homem das Nações Unidas, em 1947, a uma série de pensadores e escritores de nações membros da Unesco, que formaram a Comissão da Unesco para as Bases Filosóficas dos Direitos do Homem. Os textos recolhidos expressavam a opinião pessoal de seus autores, representando diversas correntes de pensamento filosófico e político em torno da fundamentação dos direitos humanos. O resultado do trabalho dessa Comissão foi publicado pela Unesco sob o título As bases de uma Declaração Internacional dos Direitos do Homem. Observa Maritain (1976) que houve reuniões das Comissões Nacionais da Unesco, nas quais se discutiam os fundamentos dos direitos humanos, em que era admirável o acordo havido na formulação da lista de direitos, apesar de partirem de concepções ideológicas distintas. Exitia um acordo apenas sobre a enumeração dos direitos, porém, onde tivesse lugar a discussão do porquê, originava-se uma série de disputas. Sobre o assunto, consultar Maritain (1976).
} 
Mas mais do que isso. Como sustenta Rosillo Martínez (2013, p. 18), "cremos que também é necessário realizar uma fundamentação que responda de maneira mais clara e direta à realidade da América Latina e, em geral, à do Terceiro Mundo." Isso porque uma teoria dominante que, segundo Barreto (2013, p. 6), é o resultado de uma particular perspectiva fundamentada no contexto histórico e geográfico do Ocidente, apresenta-se como universal e objetiva, reclamando para si autoridade e legitimidade para falar sobre o que significam os direitos humanos e relegando à invisibilidade a história das relações entre os modernos impérios e as colônias do Terceiro Mundo.

\section{Da fundamentação convencional (e dominante) de base jusracionalista}

A posição de Bobbio sobre o lugar secundário que a fundamentação ocupa na teoria dos direitos humanos não significa que o autor não se preocupasse com o tema. Assim como os diversos autores que têm se debruçado sobre o problema, Bobbio tinha sua própria compreensão e deixou-a bastante clara em diversos textos publicados sobre o assunto.

A vinculação entre direitos humanos e liberalismo clássico é clara e solidamente estruturada em sua obra, sobretudo no clássico Liberalismo e democracia, cujo capítulo Os direitos do homem se inicia com a afirmação de que a doutrina dos direitos do homem, elaborada pela escola do direito natural (ou jusnaturalismo), é o pressuposto filosófico do Estado Liberal, entendido como o Estado limitado em contraposição ao Estado absoluto. Jusnaturalismo, explica Bobbio (1997), é a doutrina segundo a qual todos os homens, indiscriminadamente, têm por natureza e, portanto, independentemente de sua própria vontade ou de outrem, certos direitos fundamentais, como à vida, à liberdade, à segurança e à felicidade, os quais devem ser respeitados e não invadidos pelo Estado. Segundo os cânones do jusnaturalismo moderno, pressuposto filosófico do liberalismo, a atribuição de um direito a alguém significa reconhecer que ele tem a faculdade de fazer ou não algo conforme seu desejo e também o poder de resistir contra quaisquer transgressões a esses direitos (BOBBIO, 1997, p. 11).

Esta, segundo Bobbio, foi uma revolução copernicana, que possibilitou a doutrina do Estado liberal, doutrina dos limites jurídicos do poder estatal, razão pela qual "sem individualismo, não há liberalismo." (BOBBIO, 1997, p. 12-16). Da identificação dos "direitos do homem" com o jusnaturalismo (moderno) e seu viés individualista, que caracterizam o liberalismo clássico, Bobbio (1997, p. 16) procede à constatação de que

o caminho contínuo, ainda que várias vezes interrompido, da concepção individualista da sociedade procede lentamente, indo do reconhecimento dos direitos do cidadão de cada Estado até o reconhecimento dos direitos do cidadão do mundo, cujo primeiro anúncio foi a Declaração Universal dos Direitos do Homem.

Para o autor, a Declaração Universal representou, no século XX, a consolidação de uma tradição liberal iniciada com as Declarações de Direitos dos Estados Norte-americanos e da Revolução Francesa (BOBBIO, 2004). A conceitualização de Bobbio reflete aquilo que se pode denominar 
fundamentação convencional dos direitos humanos. Mas não apenas convencional: esse é o discurso dominante na hora de justificar "para quem", "para quê", "por quê" e "de onde vem" os direitos humanos e pode assim ser traduzido nas palavras de Griffin (2008, p. 13): "a noção de direitos humanos que emergiu no fim do Iluminismo - o que pode ser razoavelmente chamado de noção iluminista - é a noção que temos hoje. Não houve desenvolvimento teórico da ideia desde então."

A comunidade científica não apenas se dedica fortemente à tarefa de fundamentar, como vêm propondo diferentes abordagens ao problema da justificação dos direitos humanos ${ }^{4}$ (fundamentação moral, utilitarista, positivista, histórica, etc.), mas na maior parte das vezes essas estratégias argumentativas se mostram filiadas ao mesmo ideário iluminista ao qual Bobbio recorre. Talvez por isso o autor repute o problema resolvido e ignore dois fatores de extrema importância, a saber: o vasto campo de disputa em torno da construção desses argumentos e as inúmeras deficiências da fundamentação de matriz jusracionalista para a compreensão de direitos que se pretendem universais.

A fundamentação jusnaturalista de cunho racionalista que, como concepção teórica, afirmou-se no ápice da modernidade ocidental (iluminismo) pode ser forçadamente resumida nos seguintes pontos: os direitos humanos constituem pretensões fundamentais básicas de todo ser humano e são decorrência da natureza humana intrínseca a todos os indivíduos humanos, que são iguais. A natureza humana radica-se em uma específica capacidade humana: a racionalidade. Os seres racionais, caracteristicamente humanos, portam uma dignidade que decorre de sua capacidade de deliberar, decidir e escolher livremente. ${ }^{5}$ É nessa dignidade - fruto da racionalidade dos indivíduos humanos - que se fundamentam os direitos humanos, ou seja, o indivíduo humano racional porta um valor moral intrínseco que justifica a titularidade de direitos que podem ser sintetizados no exercício da liberdade. Kant (1993, p. 55) explicita as bases sobre as quais a liberdade se justificará:

A liberdade (independência do arbítrio de outro), na medida em que possa subsistir com a liberdade de todos, segundo uma lei universal, é esse direito único, primitivo, próprio de cada homem, pelo simples fato de ser homem. A igualdade natural, isto é, a impossibilidade moral de ser obrigado pelos demais a mais coisas do que aquelas a que estão obrigados com respeito a nós.

A ideia de dignidade radicada na individualidade racional de cada ser humano (ou mais precisamente, de cada homem, segundo a terminologia usada nos textos clássicos sobre o tema) deriva da primazia do paradigma individualista que marca as concepções políticas e filosóficas da

\footnotetext{
4 Sobre as diversas, porém eurocêntricas abordagens ao problema da fundamentação dos direitos humanos, ver: Buchanan (2013, cap. 1-3); Griffin (2008); Beitz (2009); Cranston (1973); Foster (2008); Jones (1994).

5 Tudo tem um preço ou uma dignidade, escreve Kant. Uma coisa caracteriza-se por ter um preço e pode ser substituída por outra coisa que lhe seja equivalente; "mas quando uma coisa está acima de todo o preço, e, portanto, não permite equivalente, então tem ela dignidade." (KANT, 2003, p. 75). Ao contrário das coisas que têm um valor meramente relativo, os seres racionais denominam-se pessoas, porque a sua natureza os distingue como fins em si mesmos, ou seja, como algo que não pode ser empregado como simples meio e que, por isso, limita todo o arbítrio e é um objeto de respeito. O homem não é, pois, um fim subjetivo para a ação, mas um fim objetivo, isto é, algo cuja existência é, em si mesma, um fim. Por isso, Kant remete à existência de um princípio prático da razão que determina a vontade humana e que pressupõe que a natureza racional existe como fim em si.
} 
modernidade desde Hobbes e Descartes. A ideia segundo a qual os indivíduos são concebidos como entidades autônomas dotadas de razão e consciência será, portanto, a base para o discurso convencional e dominante dos direitos humanos, pois ela se tornou o paradigma a partir do qual se estruturaram as sociedades modernas do Ocidente e que influenciou as teorias sobre a origem do Estado. Direitos inatos do ser humano ao desenvolvimento de sua personalidade são considerados anteriores ao Estado, que é produto de um contrato livremente estabelecido por indivíduos. Os direitos subjetivos individuais são entendidos como consequência lógica e imediata da natureza humana e, por isso, valem contra o Estado, que existe para garantir as liberdades individuais preexistentes ao contrato social. Como todos os indivíduos são iguais e portam os mesmos direitos, a lei que pauta o exercício do Poder Público deve tratar todos os indivíduos de forma igual, sem distinções, e garantir que o Estado se abstenha de interferir no exercício das liberdades naturais dos indivíduos. Essa concepção é especialmente desenvolvida na obra do filósofo liberal Locke (1988).

Mas a compreensão hobbesiana sobre a natureza individualista humana, que não por acaso antecede a sua investigação a respeito da própria origem do Estado no Leviathan, foi fundamental para moldar a visão antropocêntrica do Ocidente. Hobbes atribui à razão o papel de suscitar (raised by foresight) os diversos desejos. Nesse processo, o empenho é de encontrar o bem manifesto (seeming good) e o mal manifesto (seeming evill) (HOBBES, 1974, p. 42-43), em que as faculdades da razão são responsáveis pela previsão das consequências e efeitos que determinada ação (resultado da deliberação, onde do jogo de desejos conflitantes algum se sobressaia) resultaria. Assim, embora motivado por desejos e paixões, o homem é capaz de deliberar por meio do cálculo, que determina qual o bem deve ser considerado no momento da ação, de modo que é a razão que verifica qual o bem a ser alcançado. Já a felicidade (felicity) se concretiza quando o homem alcança sucesso nas suas ações, pois as suas deliberações ou pretensões foram realizadas. Quando isso se torna contínuo, chama-se felicidade. Para Hobbes (1974), a satisfação de um desejo, ou paixão, não é o fim da felicidade, mas a garantia dos meios para que outros desejos e paixões possam ser satisfeitos. Assim, não há felicidade na satisfação de uma paixão, mas apenas a partir do momento em que se garantam os meios para satisfazer outra paixão. É por isso que a simples satisfação de um desejo não é o fim ou a causa da ação do homem, mas manter o "contínuo progresso do desejo". E é dessa premissa que se concluirá como os homens, para garantir o "poder" e os "meios para viver bem", buscam sempre mais, a fim de garantir aquilo que já têm (o poder e os meios já adquiridos). Tal compreensão corrobora a tese de que, para Hobbes (1974), o simples prazer advindo da satisfação de um desejo não é o mesmo que a felicidade. Os homens atendem a uma tendência geral de buscar sempre mais poder. Portanto, faz parte da natureza do homem a busca incessante pelos meios para se viver bem. E tal finalidade somente é alcançada quando se continua a buscar sempre mais.

Partindo do individualismo, a ética utilitarista tem regido o comportamento das sociedades ocidentais nos últimos 200 anos. $\bigcirc$ utilitarismo é uma corrente da filosofia moral que responde à questão sobre como devemos agir considerando uma ação (individual ou do governo) como boa 
ou má, correta ou incorreta segundo a sua capacidade de aumentar ou diminuir a felicidade da parte cujo interesse está em questão, ao passo que, por felicidade, entende-se o gozo dos prazeres e a segurança contra as dores. Entretanto, a dor e o prazer realizam-se no indivíduo como membro da sociedade, e, por essa razão, Bentham (1982) escreve que seria vão se deter sobre a comunidade, como um corpo fictício, sem antes considerar o interesse das pessoas individuais. Mas em que consiste o interesse da comunidade? Algo é considerado como interesse, escreve o autor, quando acrescenta à soma total dos prazeres (identificados como o bem). O interesse da comunidade é considerado como a soma dos interesses individuais dos vários membros que a compõem. Dessa forma, uma medida do governo obedece ao princípio da utilidade quando aumentar a felicidade na comunidade ao invés de diminuí-la (BENTHAM, 1982, p. 12). A felicidade do grupo (fim último da ação moral) passa pela maximização dos prazeres e pela minimização da dor de cada um de seus indivíduos-membros.

$\mathrm{Na}$ cultura ocidental, o indivíduo foi tornando-se o ser supremo e o centro de referência da vida em sociedade. Em nome da busca incessante por satisfação pessoal, identificada com o bem ou a felicidade, é legítimo invocar direitos até o ponto em que o outro indivíduo se constitua em obstáculo. Não por acaso essa é a concepção de liberdade no artigo $4^{\circ}$ da célebre Declaração Francesa dos Direitos do Homem e do Cidadão de 1789:

A liberdade consiste em poder fazer tudo que não prejudique o próximo. Assim, o exercício dos direitos naturais de cada homem não tem por limites senão aqueles que asseguram aos outros membros da sociedade o gozo dos mesmos direitos. Estes limites apenas podem ser determinados pela lei. (FRANÇA, 1789).

Como marco filosófico da cultura ocidental, o individualismo e suas ideias correlatas são invocados pela maioria dos teóricos ocidentais como fundamentos dos direitos humanos universais, permitindo-lhes que tracem uma linha contínua entre estes e os direitos naturais do homem das declarações modernas do Ocidente, de modo que a construção teórica jusracionalista é a principal base para os discursos de fundamentação dos direitos humanos até hoje. À medida que este é o discurso de fundamentação dominante, verificamos a consistência desses argumentos no que se refere ao conceito de humanidade que subjaz à importante questão da universalidade desses direitos.

\section{0 conceito de humano e suas restrições}

Um dos problemas da persistência da comunidade científica em manter o discurso de fundamentação dos direitos humanos atrelado à noção iluminista reside na sua incapacidade ou indisposição de questionar o humano que foi aí claramente definido e que, segundo esse discurso, define o sujeito de direitos humanos. A igual dignidade de todos os seres humanos - afirmada nos documentos contemporâneos - tem sido insistentemente creditada a uma essência universal do homem que, segundo Douzinas (2000, p. 187), postula a existência de um ser indistinto e indiferenciado, que se une a todos os outros em uma natureza vazia e privada de características substanciais, 
e essa concepção é a que ilustra a imagem de homem e de direitos da Revolução Francesa como uma abstração que tem o mínimo de humanidade possível. Ocorre que desde o século XIX, Marx (1970), em sua crítica aos direitos do homem, já havia demonstrado que o "homem" da Declaração Francesa não era um recipiente vazio e indeterminado, senão um sujeito extremamente repleto de substância.

Direitos humanos são sistematicamente violados em todas as partes do mundo, porém a violação não atinge a todos os indivíduos indistintamente, na medida em que há os que são mais vulneráveis à violação da dignidade que outros. Os indivíduos não são todos iguais no acesso a direitos, pois o poder é desigualmente distribuído e exercido. A proteção, de fato, desses direitos, parece estar ligada à condição daqueles sujeitos nos quais o discurso racional-individualista identifica os traços do humano.

Segundo Hall (2011, p. 10), o Iluminismo estabeleceu uma concepção essencialista ou fixa de identidade que supõe definir o próprio núcleo ou essência de nosso ser e fundamentar nossa existência como seres humanos:

O sujeito do iluminismo estava baseado numa concepção da pessoa humana como um indivíduo totalmente centrado, unificado, dotado das capacidades de razão, de consciência e de ação, cujo centro consistia num "núcleo" interior, que emergia pela primeira vez quando o sujeito nascia e com ele se desenvolvia, ainda que permanecendo essencialmente o mesmo - contínuo ou "idêntico" a ele - ao longo da existência do indivíduo. Direi mais sobre isto em seguida, mas pode-se ver que essa era uma concepção muito "individualista" do sujeito e de sua identidade (na verdade, a identidade dele: já que o sujeito do iluminismo era usualmente descrito como masculino). (HALL, 2011, p. 11, grifo do autor).

Isso tem duas implicações importantes.

Primeiro, o sujeito pós-moderno não tem uma identidade fixa, essencial ou permanente. Hall (2011, p. 13) observa que a identidade é formada e transformada continuamente em relação às formas pelas quais somos representados ou interpelados nos sistemas culturais que nos rodeiam, fazendo com que o sujeito assuma diferentes identidades em diferentes momentos, as quais não se unificam em torno de um eu coerente. Hall assume, com sustento em Harvey, que as sociedades da modernidade tardia são caracterizadas pela diferença, atravessadas por divisões e antagonismos sociais que produzem uma variedade de diferentes "posições de sujeitos" - isto é, identidades - para os indivíduos. De acordo com Hall (2011), o que está em jogo na questão das identidades é que ela se tornou politizada, na medida em que as identificações podem ser múltiplas e até mesmo contraditórias, reportando-se ao domínio sexual (identidade de gênero e orientação sexual), racial (brancos, negros, indígenas, etc002E), político (orientação ideológico-conservadora, progressista, comunista), social (relativo à classe social), etc. Enquanto indivíduos humanos, podemos assumir diferentes e múltiplas identidades, porém foi obra do Iluminismo identificar a natureza humana a uma única identidade.

Segundo, se a titularidade dos direitos humanos insiste em ser fundamentada no ideário individual-racionalista do Iluminismo, tem-se um sujeito com identidade fixa, que não corresponde, portanto, a todo e qualquer ser humano. Mesmo que o sujeito pós-moderno seja fragmentado, 
entre as diversas identidades possíveis existe aquela que corresponde ao sujeito do Iluminismo e que determina o padrão de excelência do humano. A seletividade das violações de direitos humanos demonstra que a sua observância exige muito mais do que ser um indivíduo da espécie humana (aparentemente sem identidade). Se o indivíduo for homem, heterossexual, proprietário, cristão, branco, tiver nascido em algum país do Ocidente, as chances de sua dignidade ser violada são infinitamente reduzidas. Esse é o clássico sujeito iluminista da Declaração Francesa. Se o indivíduo for mulher e/ ou homossexual e/ou indígena e/ou negra e/ou pobre e/ou tiver nascido na África ou América Latina sua vida corre grande risco de ser um repertório de violências e tragédias. Ambos são indivíduos humanos, mas para nenhum deles o gozo dos direitos humanos é natural, e, sim, decorrência de seus traços identitários e do quanto de poder ou de percepção de valor estão atrelados a essa identidade. Como observa Mignolo (2013, p. 44, grifo nosso), "o conceito de humano utilizado em conversas, nos meios de comunicação, em seminários universitários e conferências, é um conceito que deixa fora da 'humanidade' grande parcela da população mundial."

A história dessa exclusão caminha ao lado da construção dos conceitos de homem e de direitos, os quais foram inventados um pouco antes do lluminismo, pelos humanistas renascentistas nos séculos XV e XVI, e responderam à história interna dos cristãos europeus e à história externa do cristianismo no Novo Mundo. Internamente, afirmou-se a superioridade da religião cristã sobre os orientais e os pagãos, e externamente, as populações americanas e africanas foram despojadas de sua identidade, pelo que passaram a ser denominadas simplesmente índios e negros (MIGNOLO, 2013, p. 46). Mignolo (2013, p. 51) observa que homem e humano são o topo da linha de classificação racial. Raças não existem no mundo, mas no universo discursivo da teologia, filosofia e ciência ocidentais. Desde a existência da classificação racial, que se inicia no Renascimento, há um ranqueamento dos seres humanos que depende de sua aproximação aos princípios de conhecimento (crença e racionalidade; forma de vida e organização socioeconômica) e de aproximação ontológica ao Homem Vitruviano (forma e usos sociais do corpo, como postura, caminhada, dança, rituais, e rituais cristãos e não cristãos), de modo que os atores que executam e mantêm a classificação racial são os que falam pelo humano. Com o Iluminismo, a ideia de ser humano foi atualizada para significar ser racional, e racionalidade tornou-se restrita àquilo que os teóricos iluministas definiram como tal. Assim, ao final do século XVII, ser humano tornou-se mais identificado com o burguês secular que com o cristão (MIGNOLO, 2013, p. 53).

A humanidade, portanto, tem sido um conceito criado sobre categorias filosóficas e antropológicas do pensamento ocidental (MIGNOLO, 2013, p. 56). A noção de humano da modernidade ocidental é, portanto, extremamente problemática como parte da fundamentação dos direitos humanos, pois se construiu sobre a afirmação de superioridade da identidade masculina, cristã e europeia, que implica um ranqueamento e o rebaixamento da condição humana de todo o restante da humanidade. Porém, a violação seletiva de direitos humanos demonstra que a sua proteção atende, em larga medida, aos critérios de definição do homem propostos no marco da fundamentação mais influente. 


\section{Os caminhos da interculturalidade}

A noção de interculturalidade apresenta-se como importante pressuposto para desafiar as bases de sustentação do discurso convencional dos direitos humanos, pois restabelece a autoridade das perspectivas múltiplas que coexistem em espaços plurais e desiguais, como é o caso da América Latina.

Para Wolkmer (2006, p. 120, grifo do autor), esse conceito pode ser compreendido

como filosofia crítico-cultural, como horizonte de diálogo equitativo, 'como um espaço da negociação [...], como reconhecimento do pluralismo cultural [...], em que nenhuma cultura é um absoluto, senão uma possibilidade constitutivamente aberta à possível fecundação por outras culturas'. Ainda que por vezes seja associada ao multiculturalismo (ou uma forma ou variante deste), a interculturalidade tem especificidade própria, pois, tendo em conta o pluralismo cultural e a nova hermenêutica filosófica, revela-se 'um horizonte de diálogo'; define-se, conforme Isidoro Moreno, como 'um quadro comum de referência metacultural', compatibilizando 'conceitos, estratégias, identificação de problemas, valores e formas de negociação de cada parte'. Para Salas Astrain, a interculturalidade 'alude a um tipo de sociedade emergente, em que as comunidades étnicas, os grupos e classes sociais se reconhecem em suas diferenças e buscam sua mútua compreensão e valorização', o que se efetiva através de 'instâncias dialogais'. Já na perspectiva hermenêutica da filosofia, a interculturalidade 'tem como tema central a problemática da identidade, o modo de ser, o modo peculiar de pensar'. Trata-se de um discurso sobre culturas como 'síntese de elementos inovadores, transportados, assimiladas num processo histórico'. Por consequência, a interculturalidade em sua dimensão pluralista tem caráter dialógico, hermenêutico e interdisciplinar.

Diferentemente da interculturalidade, o multiculturalismo pode ser entendido a partir da concepção geral de um conjunto de fenômenos sociais, derivado da coexistência de pessoas que naturalmente se identificam com culturas diferentes (CORTINA, 2005, p. 240). Pode também ser compreendido como o contexto em que sobrepuja a reivindicação de algumas culturas por um conjunto de direitos que garantam a sua participação, efetiva e de diferentes maneiras, no cerne de democracias liberais (PIACENTINI, 2007, p. 79). A ideia central do multiculturalismo é o reconhecimento da diferença dentro da igualdade: "[...] reivindicações universalistas só podem ser realizadas de diferentes modos e nas diferentes culturas, de forma a exigir uma reconcepção da tese liberal do bem-estar e dignidade das pessoas", nas palavras de Tavares (apud PIACENTINI, 2007, p. 79).

Ademais, conforme preconiza Piacentini (2007, p. 80), multiculturalismo pode significar uma descrição e um projeto, de maneira que, enquanto nesse âmbito, prospecta-se como projeto político ou reconhecimento de diferenças, de outra banda, como descrição, representa a existência da diversidade de culturas no mundo, a coexistência dessa diversidade dentro do mesmo Estado-Nação, bem como a existência de culturas que se influenciam, dentro ou fora dos limites estatais. $\bigcirc$ multiculturalismo encontra seus principais críticos nas ideias de Jameson e Zizek (1998, p. 172) - que o veem como uma forma de imposição da ideologia do capitalismo global - e McLaren (2000, p. 292), que adverte sobre o perigo de o discurso multiculturalista, na verdade, enrustir uma pretensão homogeneizante. 
Y, desde luego, la forma ideal de la ideología de este capitalismo global es la del multiculturalismo, esa actitud que - desde una suene de posición global vacía - trata a cada cultura local como el colonizador trata al pueblo colonizado: como "nativos", cuya mayoría debe ser estudiada y "respetada" cuidadosamente. Es decir, la relación entre el colonialismo imperialista tradicional y la autocolonización capitalista global es exactamente la misma que la relación entre el imperialismo cultural occidental y el multiculturalismo: de la misma forma que en el capitalismo global existe la paradoja de la colonización sin la metrópolis colonizante de tipo Estado-Nación, en el multiculturalismo existe una distancia eurocentrista condescendiente y/o respetuosa para con las culturas locales, sin echar raices en ninguna cultura en particular. En otras palabras, el multiculturalismo es una forma de racismo negada, invertida, autorreferencial, un "racismo con distancia": "respeta" la identidad del Otro, concibiendo a éste como una comunidad "auténtica" cerrada, hacia la cual él, el multiculturalista, mantiene una distancia que se hace posible gracias a su posición universal privilegiada. El multiculturalismo es un racismo que vacía su posición de todo contenido positivo (el multiculturalismo no es directamente racista, no opone al Otro los valores particulares de su propia cultura), pero igualmente mantiene esta posición como un privilegiado punto vado de universalidad, desde el cual uno puede apreciar (y despreciar) adecuadamente las otras culturas particulares: el respeto multiculturalisra por la especificidad del Otro es precisamente la forma de reafirmar la propia superioridad. (JAMESON; ZIZEK, 1998, p. 172, grifo nosso).

A crítica dos autores, que identifica traços colonialistas no discurso multicultural - porque pressupõe a tolerância de uma cultura exótica "sob as asas" de uma cultura a qual não abre mão de ser dominante - aponta para a necessidade de ir além do projeto multicultural rumo à interculturalidade.

Walsh (2008) explica que os termos multi, pluri e interculturalidade têm genealogias e significados diferentes. Segundo a autora, pluricultural e multicultural são termos descritivos que indicam a existência de múltiplas culturas em um determinado lugar e propõem o seu reconhecimento, tolerância e respeito. Porém, ela é crítica quanto aos propósitos da política multicultural e quanto à reticência política da pluriculturalidade. Em relação ao multiculturalismo, diz a autora:

El "multi" tiene sus raices en países occidentales, en un relativismo cultural que obvia la dimensión relacional y oculta la permanencia de desigualdades e inequidades sociales. Actualmente es de mayor uso global, orientando políticas estatales y transnacionales de inclusión dentro de un modelo de corte neoliberal que busca inclusión dentro del mercado. (WALSH, 2008, p. 140).

multiculturalismo aponta, segundo ela, a existência de culturas singulares sem relação entre si e no marco de uma cultura dominante, de onde, portanto, devem provir as políticas de reconhecimento e tolerância. Sobre o pluricultural, refere tratar-se de um termo "de mayor uso en América del Sur; refleja la particularidad y realidad de la región donde pueblos indígenas y negros han convivido por siglos con blanco-mestizos y donde el mestizaje y la mezcla racial han jugado un papel significante." (WAL$\mathrm{SH}, 2008)$. Na perspectiva pluricultural, é possível reconhecer a convivência de culturas em um mesmo espaço, mas não a existência de uma inter-relação equitativa entre ambas.

Já a interculturalidade está mais além da simples constatação da existência de uma diversidade de culturas coexistindo em um mesmo espaço ou da reivindicação da tolerância e do reconhe- 
cimento da diversidade. Trata-se de algo que ainda não existe, mas de um projeto a ser construído na direção da construção de sociedades, relações e condições de vida novas e distintas. O objetivo não é simplesmente reconhecer, tolerar ou incorporar o diferente dentro da matriz e da estrutura estabelecidas, mas:

impolsionar desde la diferencia en las estructuras coloniales del poder como reto, propuesta, proceso y proyecto; es hacer reconceptualizar y re-fundar estructuras que ponen en escena y en relación equitativa lógicas, prácticas y modos culturales diversos de pensar, actuar y vivir. Así sugiere un proceso activo y permanente de negociación e interrelación donde lo propio y particular no pierdan su diferencia, sino que tengan la oportunidad y capacidad para aportar desde esta diferencia a la creación de nuevas comprensiones, convivencias, colaboraciones y solidaridades. Por eso la interculturalidad no es un hecho dado sino algo en permanente camino, insurgencia y construcción. (WALSH, 2008, p. 141).

Direitos humanos comprometidos com a promoção de uma realidade intercultural permitem não apenas a legitimação de demandas para além do ideário liberal-individualista, mas empoderam o discurso de indivíduos e grupos, como é o caso dos povos indígenas, que não se conformam aos padrões ocidentais de epistemologia, moral e estética que, em última análise, ditam a(s) identidade(s) que se podem credenciar na condição de humanos.

Ao situar as diferentes expressões culturais e modos de se fazer humano dentro de uma perspectiva equitativa, o modelo intercultural transcende o multiculturalismo como a resposta mais adequada para reestruturar discursos de fundamentação dos direitos humanos que pretendam dar conta do déficit de direitos de grupos vulnerabilizados e estigmatizados. A vulnerabilidade e o estigma decorrem justamente da pertença de alguém àqueles grupos cujas identidades não formam parte do padrão dominante ditado pelo discurso racional-individualista. Como aponta com precisão Buchanan (2013, p. 91, grifo do autor): 6

O compromisso de afirmar e proteger o igual status moral básico é talvez mais explícito na inclusão de fortes direitos contra a discriminação em razão do sexo ou raça. Historicamente, a discriminação contra as mulheres e pessoas de cor geralmente tem sido justificada com apelos a crenças sobre supostas diferenças naturais, mas como marcas de inferioridade. Em particular, a discriminação foi justificada com o argumento de que as mulheres ou pessoas de cor são naturalmente menos racionais do que os homens ou brancos, contra a suposição de fundo de que a racionalidade é um traço especialmente valioso que distingue os humanos dos chamados animais inferiores. Em tal contexto, caracterizando determinadas classes de seres humanos como menos racionais do que outros, por natureza, transmite-se uma mensagem de inferioridade, sugerindo que eles são, em certo sentido, menos do que totalmente humanos.

\footnotetext{
6 The commitment to affirming and protecting equal basic moral status is perhaps most explicit in the inclusion of strong rights against discrimination on grounds of gender or race. Historically, discrimination against women and people of color has usually been justified by appeals to beliefs about supposed natural differences, but as marks of inferiority. In particular, discrimination has been justified on the grounds that women or people of color are naturally less rational than men or whites, against the background assumption that rationality is an especially valuable trait that distinguishes humans from so-called lower animals. In such a context, characterizing certain classes of humans as less rational than others by nature conveys a message of inferiority, even suggesting that they are, in a sense, less than fully human.
} 
A interculturalidade questiona a superioridade de qualquer modelo cultural e propõe a substituição de uma perspectiva vertical por outra que seja equitativa e dialógica, e isso favorece o fortalecimento das demandas de direitos daqueles que historicamente têm sido considerados menos racionais, menos humanos e menos credenciados a titularizar qualquer direito, realidade muito presente em toda a América Latina.

\section{Considerações finais: da necessidade de se proporem novas fundamentações}

Sustentamos que Bobbio se equivoca ao situar a fundamentação dos direitos humanos em segundo plano. Como campo de disputa, a fundamentação dos direitos humanos é uma tarefa a ser realizada, porque, ao fornecer os argumentos que justificam o engajamento em torno de uma ideia, é necessária como condição para a efetividade dos direitos humanos. Mas não somente isso. Como demonstramos, existe um discurso de fundamentação construído desde (e para) a tradição ocidental e por teóricos do Ocidente que é, ao mesmo tempo, extremamente influente e incongruente. Esse discurso, ao se pretender único e inexorável, ao contrário de fortalecer os direitos humanos, enfraquece-os como ideal de vida digna para todos os seres humanos. O discurso dominante parte de uma noção de "homem" que, ao excluir grande parte dos seres humanos, acaba por legitimar as persistentes violações de direitos daqueles que, desde a Modernidade, são considerados sub-humanos.

Como observa Woessner (2013), um mapa diferente das fontes das noções de direitos humanos demonstra que o seu discurso também foi desenvolvido fora das fronteiras da Europa, entre os povos colonizados ou no Terceiro Mundo. Barreto (2013, p. 10) diz que contextualizar as teorias de direitos humanos significa mostrar as conexões genealógicas que ligam a teoria eurocêntrica aos cenários nos quais ela foi elaborada. Isso debilita a pretensa universalidade e objetividade da teoria convencional e dominante dos direitos humanos, na medida em que ela é apenas uma forma possível de responder às questões de existência e validade dos direitos humanos, mas não a única ou a mais apropriada.

Se os direitos humanos se pretendem universais e, portanto, válidos para além do Ocidente e seus sujeitos, seu discurso de fundamentação precisa desprender-se das bases eurocentradas e reconstruir-se a partir de outras visões de mundo enriquecidas pelas histórias invisíveis do outro lado da linha abissal que separa o Ocidente dos outros mundos. A noção de interculturalidade aponta caminhos, ao engajar-se em uma perspectiva equitativa entre os diversos modelos culturais que podem auxiliar na construção de uma concepção de humano mais plural e inclusiva.

\section{Referências}

BARRETO, José-Manuel. Introduction: Decolonial Strategies and Dialogue in the Human Rights Field. In: BARRETO, José-Manuel (Ed.). Human rights from a Third World Perspective. Critique, History and International Law. Cambridge Scholars Publishing, 2013. 
BARRETTO, Vicente de Paulo. Multiculturalismo e Direitos Humanos: um conflito insolúvel. In: BALDI, César Augusto (Org.). Direitos Humanos na Sociedade Cosmopolita. Rio de Janeiro: Renovar, 2004. p. 279-308.

BEITZ, Charles. The idea of human rights. Oxford: Oxford University Press, 2009.

BENTHAM, Jeremy. An introduction to the principles of morals and legislation. London: New York: Methuen, 1982.

BOBBIO, Norberto. A era dos direitos. Rio de Janeiro: Elsevier, 2004.

BOBBIO, Norberto. Liberalismo e democracia. 6. ed. São Paulo: Brasiliense, 1997.

BUCHANAN, Allen. The heart of human rights. Oxford: Oxford University Press, 2013.

COMPARATO, Fábio Konder. A Afirmação Histórica dos Direitos Humanos. 3. ed. São Paulo: Saraiva, 2003.

CORTINA, Adela. Cidadãos do Mundo - Uma teoria da cidadania. São Paulo: Loyola, 2005. In: CABALLERO, Cecilia (Org.). Justiça e Democracia - entre o universalismo e o comunitarismo. São Paulo: Landy, 2005.

CRANSTON, Maurice. What are human rights? London: Bodley Head, 1973.

DOUZINAS, Costas. The end of human rights. Oxford: Hart Publishing, 2000.

FOSTER, Steve. Human rights and civil liberties. 2. ed. New York: Oxford University Press, 2008.

FRANÇA. Declaração de direitos do homem e do cidadão. 1789. Disponível em: <http://www.direitoshumanos.usp.br/index.php/Documentos-anteriores-\%C3\%A0-cria\%C3\%A7\%C3\%A3o-da-Sociedade-das-Na\%C3\%A7\%C3\%B5es-at\%C3\%A9-1919/declaracao-de-direitos-do-homem-e-do-cidadao-1789.html>. Acesso em: 08 jan. 2010.

GRIFFIN, James. On human rights. Oxford: Oxford University Press, 2008.

HALL, Stuart. A identidade cultural na pós-modernidade. 11. ed. Rio de Janeiro: DP\&A, 2011.

HOBBES, Thomas. Leviatã ou matéria, forma e poder de um estado eclesiástico e civil. São Paulo: Abril Cultural, 1974. Coleção Os pensadores.

JAMESON, Fredric; ZIZEK, Slavoj. Estudios Culturales. Reflexiones sobre el multiculturalismo. Buenos Aires: Editorial Paidós, 1998.

JONES, Peter. Human Rights, Group Rights, and Peoples' Rights. Human Rights Quarterly, v. 21, i. 1, p. 80-107, Feb. 1999. Disponível em: <http://www.jstor.org/stable/762737>. Acesso em: 08 jan. 2010 .

JONES, Peter. Rights. Houndmills, Basingstoke, Hampshire: Macmillan, 1994.

KANT, Immanuel. Doutrina do Direito. São Paulo: Ícone Editora, 1993.

KANT, Immanuel. Fundamentação da metafísica dos costumes. São Paulo: Martin Claret, 2003. 
LOCKE, John. Two Treatises of Government. Edited by Perter Laslett. Cambridge: Cambridge University Press, 1988.

MARITAIN, Jacques. Acerca de la filosofía de los derechos del hombre. In: MARITAIN, Jacques (Ed.). Los derechos del hombre. Barcelona: Laia, 1976.

MARX, Karl. A questão judaica. São Paulo: Moraes, 1970.

MCLAREN, Peter. Multiculturalismo Revolucionário: pedagogia do dissenso para o novo milênio. Porto Alegre: Artes Médicas Sul, 2000.

MIGNOLO, Walter. Who speaks for the "Human" in Human Rights? In: BARRETO, José-Manuel (Ed.). Human rights from a Third World Perspective. Critique, History and International Law. Cambridge Scholars Publishing, 2013.

PÉREZ LUÑO, Antonio Enrique. Derechos Humanos, Estado de Derecho y Constitución. 5. ed. Madrid: Tecnos, 1995.

PIACENTINI, Dulce de Queiroz. Direitos Humanos e interculturalismo: análise da prática cultural da mutilação genital feminina. 2007. Dissertação (Mestrado em Direito)-Universidade Federal de Santa Catarina, Florianópolis, 2007.

ROSILLO MARTÍNEZ, Alejandro. Fundamentación de derechos humanos desde América Latina. Itaca: Colonia del Mar, 2013.

WALSH, Catherine. Interculturalidad, plurinacionalidad y decolonialidad: las insurgencias político-epistémicas de refundar el Estado. Tabula Rasa, Bogotá, n. 9, p. 131-152, jul./dic. 2008.

WOLKMER, Antonio Carlos. Pluralismo jurídico, direitos humanos e interculturalidade. Seqüência, Florianópolis, v. 53, p. 113-128, 2006.

Data da submissão: 26 de agosto de 2015 Avaliado em: 29 de dezembro de 2015 (AVALIADOR A) Avaliado em: 26 de junho de 2016 (AVALIADOR A) Aceito em: 12 de abril de 2017 